\title{
ANALISIS CLUSTER PENGELOMPOKAN KEPRIBADIAN WARGA BINAAN PEMASYARAKATAN DI ERA REVOLUSI INDUSTRI 4.0
}

\author{
Retno Ryani Kusumawati \\ Hannibal \\ Retika Najmamulat Asih
}

email: retno.rk@gmail.com, hannibal197018@gmail.com, retikanajma@hotmail.com

\begin{abstract}
Industrial revolution 4.0 has affected all fields, including Indonesian Ministry of Law and Human Rights whose conducting a revitalization of correctional service where capacity was the main point of clustering is now changing into clustering based on change in behavior of the prisoners, which then used as recommendation for placing prisoners into Minimum Security, Medium Security and Maximum Security Prison. Prisoner's Personality will show a prisoner's tendency to behave and to think. Personality can be measured through Big Five Personality Model consisting of Openness to Experience, Concientiousness, Extraversion, Agreeableness and Neuroticism. To simplify the placement process, the K-Means Clustering method is used. Of 137 prisoners assessed from Rangkasbitung and Serang Prison, 27 prisoners being placed to Medium Security prison, 52 prisoners to Maximum Security prison, and 58 prisoners to Minimum Security prison.
\end{abstract}

Keyword: Big Five Personality, Industrial Revolution 4.0, Prisoner's Personality, Revitalization of Correctional Service,

\begin{abstract}
ABSTRAK
Revolusi industri 4.0 akan berdampak pada segala bidang, termasuk pada Kementerian Hukum dan HAM R.I. yang salah satunya dengan melakukan revitalisasi terhadap penyelenggaraan pemasyarakatan yang sebelumnya pengelompokan Warga Binaan Pemasyarakatan (WBP) berdasarkan kapasitas menjadi pengelompokan berdasarkan perubahan perilaku yang kemudian digunakan sebagai rekomendasi penempatan ke dalam Lapas Minimum Security, Medium Security dan Maximum Security. Kepribadian WBP akan menunjukkan kecenderungan berperilaku maupun berpikir. Kepribadian dapat diukur melalui Big Five Personality Model yang terdiri dari faktor Openness to Experience, Concientiousness, Extraversion, Agreeableness, dan Neuroticism. Untuk memudahkan penempatan dilakukan analisis dengan metode K-Means Clustering. Dari 137 WBP Rutan Rangkas dan Rutan Serang yang diasesmen dapat ditempatkan 27 WBP di Lapas Medium Security, 52 orang di Lapas Maximum Security dan 58 orang di Lapas Minimum Security.

Kata Kunci: Big Five Personality, Revolusi Industri 4.0, Kepribadian Warga Binaan Pemasyarakatan (WBP), Revitalisasi Penyelenggaraan Pemasyarakatan,
\end{abstract}




\section{PENDAHULUAN}

Perkembangan teknologi informasi dari waktu ke waktu membuat perubahan dan menggeser peran sumber daya manusia menjadi mesin. Menggeser informasi yang biasanya didapat secara fisik menjadi digital. Perkembangan teknologi meningkatkan revolusi. Revolusi industri 4.0 ditandai dengan pemanfaatan internet, menghapuskan segala batas fisik yang ada. Revolusi industri 4.0 memberikan peluang dan manfaat pada berbagai bidang termasuk bisnis, ekonomi, pemerintahan juga sosial dan masyarakat. Manfaat yang paling terasa adalah segalanya menjadi lebih efisien baik dari sisi waktu maupun biaya. Namun demikian tantangan besar yang harus dihadapi adalah persoalan keamanan yang semakin kompleks, permasalahan SDM yang semakin tidak dibutuhkan, kesenjangan sosial yang semakin lebar dan persoalan-persoalan lain yang memberikan dampak negatif.

Kementerian Hukum dan Hak Asasi Manusia R.I. (disingkat Kemenkumham R.I.) adalah kementerian dalam Pemerintah Indonesia yang membidangi urusan hukum dan hak asasi manusia. Kemenkumham berada di bawah serta bertanggung jawab kepada Presiden Republik Indonesia. Kantor Wilayah (Kanwil) Kemenkumham merupakan instansi vertikal Kemenkumham yang berkedudukan di setiap provinsi, yang berada di bawah dan bertanggungjawab kepada Menteri Hukum dan Hak Asasi Manusia. Kanwil terdiri atas beberapa divisi yang membawahi sejumlah Unit Pelaksana Teknis (UPT), termasuk Kantor Imigrasi, Lembaga Pemasyarakatan (Lapas), Lapas Terbuka, Lapas Narkotika, Rumah Tahanan Negara (Rutan), Cabang Rutan, Rumah Penyimpanan Benda Sitaan Negara (Rupbasan), Balai Pemasyarakatan (Bapas), Balai Harta Peninggalan (BHP), serta Rumah Detensi Imigrasi (Rudenim).

Adanya Revolusi Industri 4.0 ini merupakan tantangan besar bagi Kemenkumham. Tantangan terberat di
UPT Lapas dan Rutan yang bertanggungjawab pada Warga Binaan Pemasyarakatan. Menjadi tantangan Kemenkumham untuk dapat merubah perilaku Warga Binaan Pemasyarakatan (WBP) yang berada dan tinggal di dalam Lapas/Rutan dalam jangka waktu sesuai pidananya. Mereka akan kembali ke masyarakat dengan perubahan perilaku dan pribadi yang lebih baik. Pola pembinaan di dalam Lapas harus disesuaikan dengan perubahan masyarakat di era revolusi ini. Tantangan Kemenkumham untuk menciptakan bentuk revolusi baru terhadap pengelolaan Lapas salah satunya dengan Revitalisasi Penyelenggaraan Pemasyarakatan. Penyelenggaraan pemasyarakatan itu sendiri bertujuan untuk mengembalikan Warga Binaan Pemasyarakatan (WBP), baik dalam hubungan dengan Tuhannya, pribadinya, sesamanya, dan juga lingkungannya, serta menjadikan WBP yang produktif dan diharapkan menjadi manusia mendiri yang berdayaguna.

Permasalahan lain dalam sistem penyelenggaraan pemasyarakatan saat ini adalah masalah overcrowding. Overcrowding merupakan masalah hampir di seluruh UPT Pemasyarakatan di mana jumlah WBP yang berada di dalam Lapas/Rutan sudah melebihi kapasitasnya. Overcrowding ini melahirkan persoalanpersoalan baru, seperti tidak seimbangnya jumlah petugas pemasyarakatan, minimnya anggaran dan sarana dikarenakan dana terkonsentrasi untuk menanggulangi makan narapidana, yang selanjutnya berakibat pada pelayanan dan pengamanan narapidana menjadi tidak maksimal. Tidak maksimalnya hal-hal tersebut akhirnya berujung pada pembinaan yang diterima oleh masing-masing WBP menjadi tidak merata sehingga berakibat pada tidak siapnya beberapa WBP untuk menghadapi kehidupan di luar Lapas, terutama dengan adanya Revolusi Industri 4.0 yang menuntut individu untuk menjadi SDM yang memiliki skill, inovasi, dan kreativitas, serta individu tersebut juga 
harus dapat memanfaatkan skill yang dimilikinya agar menghasilkan suatu produk yang kemudian dapat dipasarkan sehingga membangun jiwa entrepreneur menjadi penting untuk survive di kehidupan luar Lapas.

Sistem pemasyarakatan dengan banyaknya jumlah WBP yang telah ditempatkan yang sebelumnya mengacu pada kapasitas Lapas/Rutan akan dialihkan ke sistem revitalisasi penyelenggaraan pemasyarakatan membutuhkan waktu khusus. Dimulai dari melakukan pemetaan kepribadian WBP, infrastruktur dan disain Lapas/Rutan kemudian mengelompokkan individu-individu sesuai dengan kepribadiannya. Selanjutnya akan dilakukan penempatan/pemindahan WBP sesuai dengan kepribadiannya. Untuk membantu mempermudah kegiatan tersebut diperlukan cara yang tepat, cepat dan akurat. Dalam penelitian ini, akan dilakukan pengelompokan kepribadian WBP sebagai rekomendasi penempatan WBP.

\section{TINJAUAN PUSTAKA}

\section{Revolusi Industri 4.0}

Revolusi industri adalah perubahan besar dan radikal terhadap cara manusia memproduksi barang. Revolusi industri diawali dengan Revolusi Industri 1.0 yang ditandai dengan tumbuhnya mekanisasi dan energi berbasis uap dan air. Pada Revolusi Industri 2.0, muncul energi listrik dan motor penggerak. Selanjutnya, pada Revolusi 3.0 ditandai dengan tumbuhnya industri berbasis elektronika, teknologi informasi dan otomatisasi. Lalu, muncul Revolusi Industri 4.0 yang ditandai dengan berkembangnya Internet of/for Things (Schwab, 2017). Schwab (dalam bukunya The Fourth Industrial Revolution, 2017), menyatakan bahwa Revolusi Industri 4.0, secara fundamental, mengubah cara hidup, bekerja dan berhubungan satu sama lain

Revolusi industri ini nyatanya berdampak pada segala bidang, seperti industri manufaktur, rantai nilai produksi, faktor sosio-ekonomi, sampai dengan pendidikan dan keterampilan pekerja. Indonesia sendiri, pada dasarnya, masih belum siap secara Sumber Daya Manusia (SDM) dan pemerataannya. Dalam Revolusi Industri 4.0 ini setidaknya terdapat 3 hal yang perlu diperhatikan, yaitu kualitas SDM agar sesuai dengan kebutuhan pasar kerja yang berbasis teknologi digital; kuantitas SDM yang berkualitas, kompeten dan sesuai dengan kebutuhan industri; dan distribusi SDM yang belum merata (Haryono, 2018).

\section{Big Five Personality}

Kepribadian dapat memberikan gambaran kecenderungan seseorang untuk bertingkah laku dan berpikir, yang mana tingkah laku dan pikiran dari seseorang akan memunculkan suatu pola tindakan, sebagaimana dijelaskan oleh Pervin, Cervone, dan John (dalam Widhiastuti, 2014) bahwa kepribadian mempengaruhi pikiran, perasaan, hingga tingkah laku seseorang. Kepribadian dapat dilihat melalui beberapa model, salah satunya melalui Big Five Personality Model, yang terdiri dari 5 dimensi kepribadian yang disingkat sebagai OCEAN, (John, 1990).

OCEAN terdiri dari Openness to Experience (O) yang meliputi rasa keingitahuan, minat yang luas, kreativitas, originalitas dan imajinatif; Concientiousness (C) yang menyangkut keteraturan, ketelitian, kegigihan, dan sifat disiplin dalam menyelesaikan suatu tugas; Extraversion (E) yang menunjukkan kemampuan dalam menyesuaikan diri dengan lingkungan, keaktifan dalam berinteraksi, optimisme serta kepedulian terhadap orang lain; Agreeableness (A) yang menggambarkan kelembutan hati, kepercayaan seseorang dengan orang lain, rasa simpati dan empati, serta kemampuan untuk bekerja sama/kooperatif; serta Neuroticism $(\mathrm{N})$ yang mencakup perasaanperasaan negatif, seperti kecemasan, rasa gugup, emosinal, perasaan tidak mampu dan impulsif. 
Revitalisasi

Pemasyarakatan

Penyelenggaraan

Dalam Undang-Undang Nomor 12

Tahun 1995 tentang Pemasyarakatan menjelaskan bahwa sistem pemasyarakatan adalah suatu tatanan mengenai arah dan batas serta cara pembinaan Warga Binaan Pemasyarakatan (WBP) berdasarkan pancasila yang dilaksanakan secara terpadu antara Pembina, yang dibina, dan masyarakat untuk meningkatkan kualitas Warga Binaan Pemasyarakatan agar menyadari kesalahan, memperbaiki diri, dan tidak mengulangi tindak pidana sehingga dapat diterima kembali oleh lingkungan masyarakat, dapat aktif berperan dalam pembangunan, dan dapat hidup secara wajar sebagai warga yang baik dan bertanggung jawab. Oleh karena itu, sistem penyelenggaraan pemasyarakatan dibuat sedemikian rupa sebagai upaya untuk memulihkan WBP kepada fitrahnya dalam hubungan manusia dengan Tuhannya, manusia dengan pribadinya, dan manusia dengan lingkungannya.
Untuk mendukung dan mengarahkan, Pemerintah, dalam hal ini, Kementerian Hukum dan HAM R.I. telah mengeluarkan Peraturan Menteri Hukum dan Hak Asasi Manusia Republik Indonesia Nomor 35 Tahun 2018 tentang Revitalisasi Penyelenggaraan Pemasyarakatan yang menjelaskan bahwa Revitalisasi Penyelenggaraan Pemasyarakatan adalah suatu upaya mengoptimalisasi penyelenggaraan pemasyarakatan sebagai bentuk perlakuan terhadap Tahanan, Narapidana dan Klien serta perlindungan atas hak kepemilikan terhadap barang bukti. Dengan ini, maka Revitalisasi Penyelenggaraan Pemasyarakatan meliputi di dalamnya pembinaan Narapidana (Peraturan Menteri Hukum dan HAM R.I. Nomor 35 Tahun 2018). Melalui revitalisasi ini, WBP wajib untuk dilakukan assesmen sebagai rekomendasi dalam menempatkan Narapidana ke dalam Lapas Super Maximum Security, Maximum Security, Medium Security, dan Minimum Security. Berikut adalah matriks perbandingan antara masing-masing lapas.

Tabel 1. Matriks Perbandingan Lapas

\begin{tabular}{|c|c|c|c|c|c|}
\hline No & Indikator & $\begin{array}{c}\text { Super } \\
\text { Maximum } \\
\text { Security } \\
\end{array}$ & $\begin{array}{c}\text { Maximum } \\
\text { Security }\end{array}$ & $\begin{array}{l}\text { Medium } \\
\text { Security }\end{array}$ & $\begin{array}{c}\text { Minimum } \\
\text { Security }\end{array}$ \\
\hline 1. & Tujuan & Sadar & Disiplin & Terlatih & Terintegrasi \\
\hline 2. & $\begin{array}{l}\text { Indikator } \\
\text { Keberhasila } \\
\text { n }\end{array}$ & $\begin{array}{l}\text { - Menangkal } \\
\text { pengaruh buruk } \\
\text { yang melekat } \\
\text { pada } \\
\text { kepribadian atau } \\
\text { perilaku } \\
\text { - Merubah } \\
\text { konsep diri } \\
\text { tentnag } \\
\text { kerpibadian atau } \\
\text { perilaku }\end{array}$ & $\begin{array}{l}\text { - Membentuk } \\
\text { kedisiplinan diri } \\
\text { - Membangun } \\
\text { kepatuhan } \\
\text { terhadap aturan }\end{array}$ & $\begin{array}{l}\text { - Memberikan } \\
\text { pendidikan dan } \\
\text { pelatihan } \\
\text { - Memberikan } \\
\text { jaminan } \\
\text { kesinambungan } \\
\text { pelatihan } \\
\text { dengan pangsa } \\
\text { pasar } \\
\text { - Memberikan } \\
\text { kesempatan } \\
\text { pembelajaran di } \\
\text { area } \\
\text { produksi/magan } \\
\text { g }\end{array}$ & $\begin{array}{l}\text { Membangun } \\
\text { interaksi yang } \\
\text { sehat dengan } \\
\text { masyarakat } \\
\text { Mempekerjakan } \\
\text { sesuai dengan } \\
\text { kompetensi } \\
\text { Memberikan } \\
\text { penambahan } \\
\text { nilai usaha dari } \\
\text { produksi }\end{array}$ \\
\hline 3. & Program & $\begin{array}{l}\text { - Disengagement } \\
\text { - Tidak ada }\end{array}$ & $\begin{array}{l}\text { - Konsenstrasi } \\
\text { Sistem }\end{array}$ & $\begin{array}{r}\text { Vocation } \\
\text { al Training/Life }\end{array}$ & $\begin{array}{l}\text { - Integrasi } \\
\text { - Ada pemberian }\end{array}$ \\
\hline
\end{tabular}




\begin{tabular}{|c|c|c|c|c|c|}
\hline No & Indikator & $\begin{array}{c}\text { Super } \\
\text { Maximum } \\
\text { Security }\end{array}$ & $\begin{array}{l}\text { Maximum } \\
\text { Security }\end{array}$ & $\begin{array}{l}\text { Medium } \\
\text { Security }\end{array}$ & $\begin{array}{c}\text { Minimum } \\
\text { Security }\end{array}$ \\
\hline & & $\begin{array}{l}\text { pemberian } \\
\text { remisi } \\
\text { - Tidak ada } \\
\text { program } \\
\text { reintegrasi } \\
\text { - Layanan } \\
\text { Kunjungan } \\
\text { menggunakan } \\
\text { Multimedia/Vid } \\
\text { eo Conference } \\
\text { (tidak berada } \\
\text { dalam satu } \\
\text { gedung) }\end{array}$ & $\begin{array}{l}\text { - Ada pemberian } \\
\text { remisi } \\
\text { - Tidak ada } \\
\text { program } \\
\text { reintegrasi } \\
\text { - Layanan } \\
\text { Kunjungan } \\
\text { menggunakan } \\
\text { interkom dan } \\
\text { sekat pemisah } \\
\text { (berada dalam } \\
\text { satu gedung tapi } \\
\text { tidak ada kontak } \\
\text { fisik) }\end{array}$ & 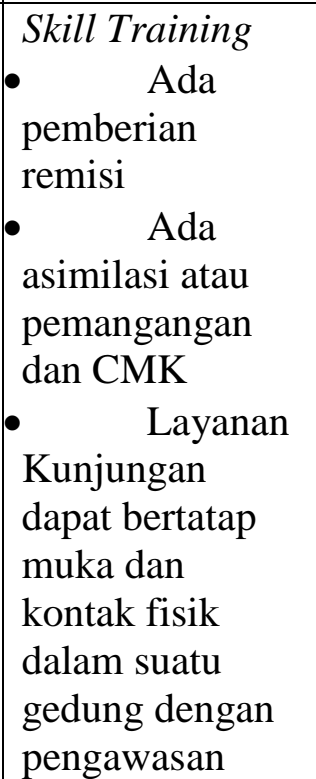 & $\begin{array}{l}\text { remisi } \\
\text { - Ada CMK, PB, } \\
\text { CB, CMB } \\
\text { - Layanan } \\
\text { Kunjungan } \\
\text { dapat bertatap } \\
\text { muka dan } \\
\text { kontak fisik } \\
\text { dalam suatu } \\
\text { gedung dan } \\
\text { diberikan izin } \\
\text { family visit }\end{array}$ \\
\hline 4. & $\begin{array}{l}\text { Aksesibilita } \\
\text { S }\end{array}$ & $\begin{array}{l}\text { - Pergerakan } \\
\text { individu tidak } \\
\text { ada } \\
\text { - Pengawasan } \\
\text { individual } \\
\text { - Komunikasi } \\
\text { hanya dengan } \\
\text { petugas dan } \\
\text { secara terbatas }\end{array}$ & $\begin{array}{l}\text { - Pergerakan } \\
\text { individu terbatas } \\
\text { - Pengawasan } \\
\text { kelompok } \\
\text { - Komunikasi } \\
\text { dengan petugas } \\
\text { secara bebas } \\
\text { - Komunikasi } \\
\text { dengan } \\
\text { narapidana } \\
\text { secara terbatas }\end{array}$ & $\begin{array}{l}\text { - Pergerak } \\
\text { an individu } \\
\text { terbatas } \\
\text { - } \quad \text { Pengawa } \\
\text { san kelompok } \\
\text { - Komunik } \\
\text { asi dengan } \\
\text { petugas secara } \\
\text { bebas } \\
\text { - Komunik } \\
\text { asi dengan } \\
\text { narapidana } \\
\text { secara bebas } \\
\text { - Komunik } \\
\text { asi dengan } \\
\text { keluarga secara } \\
\text { terbatas }\end{array}$ & $\begin{array}{l}\text { Pergerakan } \\
\text { individu bebas } \\
\text { - Pengawasan } \\
\text { kelompok } \\
\text { - Komunikasi } \\
\text { dengan petugas } \\
\text { secara bebas } \\
\text { - Komunikasi } \\
\text { dengan } \\
\text { narapidana } \\
\text { secara bebas } \\
\text { Komunikasi } \\
\text { dengan keluarga } \\
\text { secara bebas }\end{array}$ \\
\hline 5. & Penempatan & $\begin{array}{l}\text { Narapidana } \\
\text { berdasarkan } \\
\text { hasil assesmen } \\
\text { dikategorikan } \\
\text { memiliki tingkat } \\
\text { kesadaran sangat } \\
\text { rendah/risiko } \\
\text { tinggi }\end{array}$ & $\begin{array}{l}\text { Narapidana dari } \\
\text { Lapas Super } \\
\text { Maximum } \\
\text { Security atau } \\
\text { terpidana } \\
\text { berdasarkan } \\
\text { hasil assesmen } \\
\text { memiliki tingkat } \\
\text { kesadaran } \\
\text { rendah }\end{array}$ & $\begin{array}{l}\text { Narapidana dari } \\
\text { Lapas Maximum } \\
\text { Security atau } \\
\text { Terpidana } \\
\text { berdasarkan } \\
\text { hasil assesmen } \\
\text { memiliki tingkat } \\
\text { kesadaran } \\
\text { sedang }\end{array}$ & $\begin{array}{l}\text { Narapidana dari } \\
\text { Lapas Medium } \\
\text { Security } \\
\text { berdasarkan } \\
\text { hasil assesmen } \\
\text { memiliki tingkat } \\
\text { kesadaran tinggi }\end{array}$ \\
\hline
\end{tabular}

Sumber : Direktorat Jenderal Pemasyarakatan, 2018 
Dengan melihat indikator-indikator di atas, maka pada masing-masing tingkatan lapas terdapat pembinaan sebagai berikut :

Tabel 2. Tingkatan Lapas

\begin{tabular}{|c|c|c|}
\hline Tingkatan Lapas & Jenis Pembinaan & Penanggungjawab \\
\hline $\begin{array}{l}\text { Lapas Super } \\
\text { Maximum Security }\end{array}$ & $\begin{array}{l}\text { a.Pembinaan kesadaran beragama } \\
\text { b. Pembinaan kesadaran } \\
\text { berbangsa dan bernegara } \\
\text { c.Pembinaan kesadaran hukum } \\
\text { d. Konseling psikologi }\end{array}$ & $\begin{array}{l}\text { Direktorat Jenderal } \\
\text { Pemasyarakatan }\end{array}$ \\
\hline $\begin{array}{l}\text { Lapas Maximum } \\
\text { Security }\end{array}$ & $\begin{array}{l}\text { a.Pembinaan kesadaran beragama } \\
\text { b. Pembinaan kesadaran } \\
\text { berbangsa dan bernegara } \\
\text { c.Pembinaan kesadaran hukum } \\
\text { d. Pembinaan kemampuan } \\
\text { intelektual } \\
\text { e. Konseling psikologi } \\
\text { f. Rehabilitasi }\end{array}$ & $\begin{array}{l}\text { Kantor Wilayah } \\
\text { Kementerian Hukum dan } \\
\text { HAM R.I. }\end{array}$ \\
\hline $\begin{array}{l}\text { Lapas Medium } \\
\text { Security }\end{array}$ & $\begin{array}{l}\text { a.Pendidikan dan pelatihan } \\
\text { keterampilan tingkat pemula } \\
\text { b. Pendidikan dan pelatihan } \\
\text { keterampilan tingkat lanjutan } \\
\text { c.Pendidikan dan pelatihan } \\
\text { keterampilan tingkat mahir }\end{array}$ & $\begin{array}{l}\text { Kantor Wilayah } \\
\text { Kementerian Hukum dan } \\
\text { HAM R.I. }\end{array}$ \\
\hline $\begin{array}{l}\text { Lapas Minimum } \\
\text { Security }\end{array}$ & $\begin{array}{l}\text { Produksi barang atau jasa berskala } \\
\text { industri }\end{array}$ & $\begin{array}{l}\text { Kantor Wilayah } \\
\text { Kementerian Hukum dan } \\
\text { HAM R.I. }\end{array}$ \\
\hline
\end{tabular}

Sumber : Permenkumham R.I. Nomor 35 Tahun 2018

Berikut ini ketentuan kepribadian sebagai rekomendasi penempatan WBP dengan mengacu pada Peraturan Menteri Hukum dan HAM R.I. Nomor 35 Tahun 2018.

Tabel 3. Ketentuan Kepribadian WBP

\begin{tabular}{|c|c|c|}
\hline $\begin{array}{c}\text { Tingkatan } \\
\text { Lapas }\end{array}$ & Indikator Perilaku WBP & Kepribadian WBP \\
\hline $\begin{array}{l}\text { Lapas } \\
\text { Super } \\
\text { Maximum } \\
\text { Security }\end{array}$ & $\begin{array}{l}\text { a. Pernah/ada kecenderungan melarikan diri/berencana } \\
\text { untuk melarikan diri dari Lapas, baik dengan/tanpa } \\
\text { bantuan orang lain/jaringan, dan membahayakan } \\
\text { orang lain atau tidak } \\
\text { b. Pernah/ada kecenderungan melakukan kekerasan, } \\
\text { baik secara individual maupun berkelompok } \\
\text { c. Masih aktif sebagai anggota kelompok/jaringan } \\
\text { ekstrimis/fundamentalis berbasis agama dan/atau } \\
\text { sebagai anggota kelompok/jaringan separatisme } \\
\text { d. Pernah/masih memegang posisi penting dalam } \\
\text { kelompok/jaringan ekstrimis/fundamentalis berbasis } \\
\text { agama dan/atau sebagai anggota kelompok/jaringan } \\
\text { separatisme } \\
\text { e. Pernah mendapatkan pelatihan militer, misalnya }\end{array}$ & $\begin{array}{ll}\text { - } & \text { Neuroticism }(\mathrm{N}) \\
& \text { tinggi } \\
\text { - } & \text { Extraversion }(\mathrm{E}) \\
& \text { rendah } \\
\text { - } & \text { Openness to } \\
& \text { Experience }(\mathrm{O}) \\
& \text { rendah } \\
\text { - } & \text { Agreeableness }(\mathrm{A}) \\
\text { rendah } \\
\text { - Concientiousness } \\
\text { (C) tinggi }\end{array}$ \\
\hline
\end{tabular}




\begin{tabular}{|c|c|c|}
\hline Tingkatan & Indikator Perilaku WBP & Kepribadian WBP \\
\hline & $\begin{array}{l}\text { mantan TNI atau mantan Polisi, dan/atau pelatihan } \\
\text { paramiliter } \\
\text { f. Pernah terlibat dan/atau memegang posisi penting } \\
\text { dalam aksi unjuk rasa } \\
\text { g. Pernah diproses secara hukum lebih dari } 3 \text { kali } \\
\text { karena pelanggaran lalu lintas yang bukan } \\
\text { kecelakaan } \\
\text { h. Pernah diberhentikan dari tempat kerja karena } \\
\text { melakukan pelanggaran indisipliner } \\
\text { i. Pernah didiagnosis memiliki kecenderungan } \\
\text { agresivitas yang sangat tinggi/kepribadian anti } \\
\text { sosial/kepribadian anti otoritas/memiliki } \\
\text { kepribadian temperamen } \\
\text { j. Pernah didiagnosa oleh dokter memiliki penyakit } \\
\text { menular berbahaya yang tidak bisa/sulit } \\
\text { disembuhkan } \\
\text { k. Pernah didiagnosa oleh psikolog/psikiater memiliki } \\
\text { gangguan psikologis berat } \\
\text { 1. Pernah didiagnosa oleh psikolog/psikiater memiliki } \\
\text { intelegensi di bawah rata-rata } \\
\text { m. Memiliki kekuatan/pengaruh politik yang besar }\end{array}$ & \\
\hline $\begin{array}{l}\text { Lapas } \\
\text { Maximum } \\
\text { Security }\end{array}$ & $\begin{array}{l}\text { a. Ada kecenderungan melarikan diri/berencana } \\
\text { untuk melarikan diri dari Lapas, baik dengan/tanpa } \\
\text { bantuan orang lain/jaringan, dan membahayakan } \\
\text { orang lain atau tidak } \\
\text { b. Ada kecenderungan melakukan kekerasan, baik } \\
\text { secara individual maupun berkelompok } \\
\text { c. Masih aktif sebagai anggota kelompok/jaringan } \\
\text { ekstrimis/fundamentalis berbasis agama dan/atau } \\
\text { sebagai anggota kelompok/jaringan separatisme } \\
\text { d. Pernah mendapatkan pelatihan militer, misalnya } \\
\text { mantan TNI atau mantan Polisi, dan/atau pelatihan } \\
\text { paramiliter } \\
\text { e. Pernah terlibat dalam aksi unjuk rasa } \\
\text { f. Pernah diproses secara hukum lebih dari } 3 \text { kali } \\
\text { karena pelanggaran lalu lintas yang bukan } \\
\text { kecelakaan } \\
\text { g. Pernah diberhentikan dari tempat kerja karena } \\
\text { melakukan pelanggaran indisipliner } \\
\text { h. Pernah didiagnosis memiliki kecenderungan } \\
\text { agresivitas yang tinggi/kepribadian anti } \\
\text { sosial/kepribadian anti otoritas } \\
\text { i. Pernah didiagnosa oleh dokter memiliki penyakit } \\
\text { menular berbahaya yang tidak bisa/sulit/bisa } \\
\text { disembuhkan } \\
\text { j. Pernah didiagnosa oleh psikolog/psikiater memiliki } \\
\text { gangguan psikologis tingkat sedang } \\
\text { k. Pernah didiagnosa oleh psikolog/psikiater memiliki }\end{array}$ & $\begin{array}{ll}\text { - } & \text { Neuroticism }(\mathrm{N}) \\
& \text { sedang } \\
\text { - } & \text { Extraversion }(\mathrm{E}) \\
& \text { rendah } \\
\text { - } & \text { Openness to } \\
& \text { Experience }(\mathrm{O}) \\
& \text { rendah } \\
\text { - } & \text { Agreeableness (A) } \\
\text { rendah } \\
\text { - Concientiousness } \\
\text { (C) sedang }\end{array}$ \\
\hline
\end{tabular}




\begin{tabular}{|c|c|c|}
\hline $\begin{array}{c}\text { Tingkatan } \\
\text { Lapas }\end{array}$ & Indikator Perilaku WBP & Kepribadian WBP \\
\hline & intelegensi di bawah rata-rata & \\
\hline $\begin{array}{l}\text { Lapas } \\
\text { Medium } \\
\text { Security }\end{array}$ & $\begin{array}{l}\text { a. Tidak ada kecenderungan untuk melarikan diri dari } \\
\text { Lapas } \\
\text { b. Tidak ada kecenderungan untuk melakukan } \\
\text { kekerasan, baik secara individual maupun } \\
\text { berkelompok } \\
\text { c. Tidak pernah terlibat sebagai anggota } \\
\text { kelompok/jaringan ekstrimis/fundamentalis berbasis } \\
\text { agama dan/atau sebagai anggota kelompok/jaringan } \\
\text { separatisme } \\
\text { d. Secara psikologis, tingkat agresivitas rendah dan } \\
\text { tidak ada kecenderungan berkepribadian anti } \\
\text { sosial/anti otoritas } \\
\text { e. Telah didiagnosa oleh dokter bahwa tidak mengidap } \\
\text { penyakit menular } \\
\text { f. Telah didiagnosa oleh psikolog/psikiater memiliki } \\
\text { gangguan psikologis ringan atau tidak memiliki } \\
\text { gangguan psikologis } \\
\text { g. Siap untuk menerima pelatihan-pelatihan, baik siap } \\
\text { secara fisik maupun mental }\end{array}$ & $\begin{array}{ll}\text { - } & \text { Neuroticism }(\mathrm{N}) \\
& \text { rendah } \\
\text { - } & \text { Extraversion }(\mathrm{E}) \\
& \text { rendah } \\
\text { - } & \text { Openness to } \\
& \text { Experience }(\mathrm{O}) \\
& \text { sedang } \\
\text { - } & \text { Agreeableness }(\mathrm{A}) \\
& \text { sedang } \\
\text { - } & \text { Concientiousness } \\
& \text { (C) rendah }\end{array}$ \\
\hline $\begin{array}{l}\text { Lapas } \\
\text { Minimum } \\
\text { Security }\end{array}$ & $\begin{array}{l}\text { a. Tidak ada keinginan untuk melarikan diri dari Lapas } \\
\text { b. Tidak ada kecenderungan/tidak menyukai perilaku } \\
\text { kekerasan } \\
\text { c. Tidak pernah terlibat sebagai anggota } \\
\text { kelompok/jaringan ekstrimis/fundamentalis berbasis } \\
\text { agama dan/atau sebagai anggota kelompok/jaringan } \\
\text { separatisme } \\
\text { d. Secara psikologis, tingkat agresivitas rendah dan } \\
\text { memiliki kemampuan untuk berinteraksi sosial } \\
\text { dengan baik } \\
\text { e. Telah didiagnosa oleh dokter bahwa tidak mengidap } \\
\text { penyakit menular } \\
\text { f. Telah didiagnosa oleh psikolog/psikiater tidak } \\
\text { memiliki gangguan psikologis } \\
\text { g. Memiliki keterampilan untuk menghasilkan suatu } \\
\text { produk yang dapat dipasarkan } \\
\text { h. Dapat menciptakan inovasi-inovasi, baik inovasi } \\
\text { produk yang dihasilkan, proses produksinya, hingga } \\
\text { cara memasarkan produk }\end{array}$ & $\begin{array}{ll}-\quad \text { Neuroticism }(\mathrm{N}) \\
\text { sedang } \\
\text { - } \\
\text { Extraversion }(\mathrm{E}) \\
\text { sedang } \\
\text { - Openness to } \\
\text { Experience (O) } \\
\text { tinggi } \\
\text { - Agreeableness (A) } \\
\text { tinggi } \\
\text { - Concientiousness } \\
\text { (C) tinggi }\end{array}$ \\
\hline
\end{tabular}

Sumber: Kanwil Kemenkumham Banten, 2019

\section{METODE PENELITIAN}

Penelitian ini menggunakan data primer yang berasal dari rekam data kepribadian WBP dari Rutan Serang dan Rutan Rangkas. Jumlah WBP yang menjadi obyek penelitian adalah sebanyak 137 WBP. Variabel independen yang digunakan dalam penelitian ini adalah:

1. Openness to Experience

2. Concientiousness

3. Extraversion 


\section{Agreeableness}

5. Neuroticism

Penelitian ini akan mengelompokkan WBP berdasarkan kepribadiannya dengan menggunakan analisis cluster yang ada di SPSS. Mengikuti data yang ada, untuk proses clustering menggunakan metode Non-Hirarchical atau K-Means Cluster. Metode K-Means memproses semua obyek secara sekaligus. Proses ini dimulai dengan penentuan jumlah cluster terlebih dahulu. Jumlah cluster yang diinginkan adalah sesuai dengan yang menjadi tanggung jawab Kanwil Kemenkumham yaitu sebanyak 3 cluster yaitu Lapas Maximum Security, Lapas Medium Security dan Lapas Minimum Security.

Setelah dilakukan analisis, dilanjutkan dengan penafsiran setiap cluster untuk melihat perbedaan variabel pada cluster yang terbentuk dan jumlah anggota di setiap cluster.

\section{ANALISA DAN PEMBAHASAN}

Responden pada penelitian ini adalah Warga Binaan Pemasyarakatan (WBP) pada Lapas/Rutan jajaran Kantor Wilayah Kementerian Hukum dan HAM Banten sejumlah 137 orang. Statistik deskriptif digunakan untuk mengetahui bagaimana gambaran umum tentang penyebaran WBP pada masing-masing. Statistik deskriptif kepribadian WBP dapat dilihat pada tabel berikut:

Tabel 4. Statistik Deskriptif Kepribadian WBP

\begin{tabular}{|l|c|c|c|c|c|}
\hline & & Descriptive Statistics & $\begin{array}{c}\text { Std. } \\
\text { Deviation }\end{array}$ \\
\hline Openness & 137 & 5 & 16 & 11.23 & 1.819 \\
Concientiousness & 137 & 6 & 15 & 12.09 & 1.873 \\
Extraversion & 137 & 8 & 15 & 10.73 & 1.512 \\
Agreeableness & 137 & 5 & 16 & 11.31 & 1.897 \\
Neuroticism & 137 & 6 & 15 & 10.53 & 1.839 \\
Valid N (listwise) & 137 & & & & \\
\hline
\end{tabular}

Selanjutnya dapat dilakukan penormaan skor kepribadian dengan menggunakan ukuran pemusatan data yang membagi data menjadi empat bagian sama banyak yaitu masingmasing sebanyak $1 / 4 \mathrm{~N}$ atau disebut Kuartil (Q). Kuartil terbagi menjadi tiga yaitu kuartil 1 (Q1), kuartil 2 (Q2), dan kuartil 3 (Q3). Ketiga kuartil ini membagi semua distribusi dari frekuensi data yang akan dihitung menjadi empat bagian yang sama banyak dan masingmasing sebanyak $1 / 4$ N. Hasilnya sebagai berikut:

Tabel 5. Penormaan Skor Kepribadian

\begin{tabular}{|c|c|}
\hline Skor Kepribadian & Keterangan \\
\hline$<11$ & Rendah \\
\hline 11 & Sedang \\
\hline$>11$ & Tinggi \\
\hline
\end{tabular}

Langkah berikutnya dilakukan analisis cluster dengan metode Non-Hierarchical Cluster atau K-Means Cluster dengan program bantu SPSS versi 23. Dari proses cluster, terjadi 3 cluster atau kelompok responden yang masing-masing kelompok mempunyai ciri yang berbeda satu dengan yang lain. Rata-rata skor kepribadian responden adalah sebagai berikut: 
Tabel 6. Kepribadian Sesuai Cluster

\begin{tabular}{|c|c|c|c|}
\hline Kepribadian & Cluster 1 & Cluster 2 & Cluster 3 \\
\hline Openness to Experience & 11 & 10 & 12 \\
\hline Concientiousness & 9 & 13 & 13 \\
\hline Extraversion & 10 & 10 & 11 \\
\hline Agreeableness & 11 & 10 & 13 \\
\hline Neuroticism & 9 & 11 & 11 \\
\hline
\end{tabular}

\section{Penafsiran setiap Cluster}

\section{Cluster I}

Cluster 1 berisi WBP yang mempunyai kepribadian sebagai berikut:

Tabel 7. Kepribadian Pada Cluster 1

\begin{tabular}{|c|c|c|}
\hline Kepribadian & Cluster 1 & Keterangan \\
\hline Openness to Experience & 11 & Sedang \\
\hline Concientiousness & 9 & Rendah \\
\hline Extraversion & 10 & Rendah \\
\hline Agreeableness & 11 & Sedang \\
\hline Neuroticism & 9 & Rendah \\
\hline
\end{tabular}

WBP pada Cluster 1 menunjukkan bahwa rata-rata WBP cukup terbuka terhadap wawasan baru, namun tetap lebih menyukai hal-hal yang bersifat konvensional dan sederhana. Selain itu, WBP termasuk pribadi yang seringkali bekerja tanpa tujuan, cenderung mudah menyerah, dan malas. WBP pada cluster ini juga agak tertutup, tidak begitu menikmati interaksi sosial, agak sulit berempati, namun tidak sulit juga untuk kooperatif jika diminta. WBP ini juga termasuk pribadi yang tenang, santai, serta kuat secara emosional. Melihat profil tersebut, dapat diduga kecenderungan WBP pada Cluster 1 untuk ditempatkan di Lapas Medium Security.

Pada Lapas Medium Security, WBP akan mendapatkan pembinaan berupa pelatihanpelatihan untuk meningkatkan/menambah keterampilannya sehingga WBP memiliki suatu produk yang harapannya dapat dipasarkan. Pembinaan sesuai dengan kepribadian WBP pada cluster ini di mana diperlukan pembinaan yang memaksa WBP untuk bekerja dengan tujuan tertentu, serta memperkuat kemampuannya bersosialisasi karena dihadapkan dengan orang lain juga mendapatkan pelatihan yang sama. Selain itu, pribadi WBP pada cluster ini yang tidak sulit untuk kooperatif dan juga memiliki emosi yang tenang/tidak emosional sehingga tidak akan ada kendala dalam pemberian pembinaan.

Cluster 2

Cluster 2 berisi WBP yang mempunyai kepribadian sebagai berikut :

Tabel 8. Kepribadian Pada Cluster 2

\begin{tabular}{|c|c|c|}
\hline Kepribadian & Cluster 2 & Keterangan \\
\hline Openness to Experience & 10 & Rendah \\
\hline Concientiousness & 13 & Tinggi \\
\hline Extraversion & 10 & Rendah \\
\hline Agreeableness & 10 & Rendah \\
\hline Neuroticism & 11 & Sedang \\
\hline
\end{tabular}


WBP pada Cluster 2 menunjukkan bahwa rata-rata memiliki kecenderungan untuk tidak kooperatif, sinis, kasar, bahkan manipulatif, kejam, dan mudah curiga terhadap orang lain. Ditambah lagi dengan tingkat extraversion yang rendah menunjukkan WBP adalah tipe pendiam, kurang ramah, dan lebih suka menyendiri. WBP pada cluster ini juga memiliki kecenderungan ke arah impulsif dan mudah terpancing emosinya, walaupun jika tidak ada yang mengganggu, WBP cenderung terlihat tenang. Hal ini menunjukkan adanya kemungkinan WBP melakukan tindak kekerasan, selain itu ditambah dengan sifat pekerja keras, rapi, dan hati-hati, tidak menutup kemungkinan, WBP dapat mengatur rencana untuk melarikan diri yang teliti sehingga tidak diketahui oleh pihak lain. Oleh karena itu, melihat profil kepribadian tersebut, WBP pada Cluster 2 sebaiknya ditempatkan di Lapas Maximum Security.

\section{Cluster 3}

Cluster 3 berisi WBP yang mempunyai kepribadian sebagai berikut :

Tabel 9. Kepribadian Pada Cluster 3

\begin{tabular}{|c|c|c|}
\hline Kepribadian & Cluster 3 & Keterangan \\
\hline Openness to Experience & 12 & Tinggi \\
\hline Concientiousness & 13 & Tinggi \\
\hline Extraversion & 11 & Sedang \\
\hline Agreeableness & 13 & Tinggi \\
\hline Neuroticism & 11 & Sedang \\
\hline
\end{tabular}

WBP pada Cluster 3 menunjukkan bahwa rata-rata WBP memiliki minat yang luas, kreatif, dan rasa ingin tahu yang besar. Selain itu, didukung dengan pribadi pekerja keras, teratur, rapi, dan hati-hati dalam bekerja, serta kooperatif, empati, dan penurut. Walaupun WBP pada cluster ini rata-rata memiliki kecenderungan mudah cemas dan gugup, namun selama tidak ada pemicu, WBP termasuk pribadi yang tenang. WBP pada cluster ini juga menikmati bersosialisasi dengan orang lain, namun pada saat-saat tertentu membutuhkan juga waktu untuk sendiri. Melihat profil kepribadian tersebut, WBP pada cluster ini sesuai jika ditempatkan pada Lapas Minimum Security. Kepribadiannya yang kreatif, pekerja keras, kooperatif, serta ketelitiannya dalam bekerja menunjukkan kemampuannya untuk menjadi individu-individu yang produktif, terutama jika disertai dengan keterampilan yang sesuai dengan minat dan bakatnya.

Dari hasil analisis cluster tersebut dapat diketahui WBP-WBP yang akan ditempatkan yaitu:

Tabel 10. Tingkatan Lapas

\begin{tabular}{|c|c|}
\hline Tingkatan Lapas & $\begin{array}{c}\text { Jumlah WBP } \\
\text { Ditempatkan }\end{array}$ \\
\hline Medium Security & 27 \\
\hline Maximum Security & 52 \\
\hline Minimum Security & 58 \\
\hline
\end{tabular}




\section{SIMPULAN}

Berdasarkan hasil analisis yang telah dibahas diketahui bahwa dari 137 WBP yang sebelumnya ditempatkan di Rutan Rangkas dan Serang akan ditempatkan sesuai kepribadiannya. WBP dengan kepribadian Openness to Experience tinggi, Concientiousness tinggi, Extraversion sedang, Agreeableness tinggi dan Neuroticism sedang akan ditempatkan ke Lapas Minimum Security. Dalam penelitian ini sebanyak 58 orang akan ditempatkan di Lapas Minimum Security.

WBP dengan kepribadian Openness to Experience sedang, Concientiousness tinggi, Extraversion rendah, Agreeableness sedang dan Neuroticism rendah akan ditempatkan ke Lapas Medium Security. Dalam penelitian ini sebanyak 27 orang akan ditempatkan di Lapas Medium Security.

WBP dengan kepribadian Openness to Experience rendah, Concientiousness tinggi, Extraversion sedang, Agreeableness sedang dan Neuroticism rendah akan ditempatkan ke Lapas Maximum Security. Dalam penelitian ini sebanyak 52 orang akan ditempatkan di Lapas Maximum Security.

\section{KETERBATASAN DAN SARAN}

Penelitian ini merupakan studi pendahuluan penggunaan metode $K$-Means yang diolah menggunakan SPSS. Apabila dibandingkan dengan perhitungan manual yang dilakukan oleh pegawai Kemenkumham tidak ada perbedaan yang berarti dari hasilnya. Tetapi perhitungan manual dengan menggunakan bantuan program Ms-Excel memakan waktu cukup lama dan dilakukan dengan banyak tahapan.

Jumlah WBP di Banten untuk seluruh UPT kurang lebih 11.000 orang. Untuk Lapas-lapas yang ada telah disiapkan design dan infrastruktur sesuai dengan Permenkumham Nomor 11 Tahun 2017 tentang Grand Design Penanganan Overcrowded pada Rumah Tahanan
Negara dan Lembaga Pemasyarakatan yang telah mengadopsi teknologi di era 4.0 .

Selanjutnya, dengan penempatan yang disesuaikan dengan kepribadian WBP, diharapkan WBP mendapatkan pembinaan yang sesuai dengan kondisi dan situasinya. Penempatan WBP tersebut juga diharapkan dapat mengurangi overcrowding yang terjadi hampir di seluruh Unit Pelaksana Teknis Pemasyarakatan, baik di jajaran Kantor Wilayah Kementerian Hukum dan HAM Banten dan di seluruh Kantor Wilayah Kementerian Hukum dan HAM Provinsi lainnya. Dengan berkurangnya overcrowding, WBP juga mendapatkan pembinaan secara merata sehingga dapat menjadi individu yang siap menghadapi kehidupan diluar Lapas/Rutan dan berkontribusi sebagai SDM yang produktif di era Revolusi Industri 4.0.

Metode K-Means Clustering ini dapat digunakan sebagai metode pengelompokan WBP berdasarkan kepribadiannya pada Unit Pelaksana Teknis lainnya di lingkungan Kantor Wilayah Kementerian Hukum dan HAM Banten serta dapat dikembangkan lagi melalui berbagai alat ukur mengingat metode K-Means Clustering ini lebih praktis dan cepat.

\section{DAFTAR PUSTAKA}

Haryono, Siswoyo. (2018). Re-Orientasi Pengembangan SDM pada Revolusi Industri 4.0. Universitas Muhammadiyah Yogyakarta. Yogyakarta.

John, O. P. (1990). "The Big Five Factor Taxonomy: Dimension of Personality in the Natural Language \& in Questionaires". In L. Pervin (Ed.) Handbook of Personality: Theory \& Research. (pp. 66-100). Guilford Press. New York.

Keputusan Direktur Jenderal Pemasyarakatan Kementerian Hukum dan Hak Asasi Manusia Republik 
Indonesia Nomor : PAS-15.PR.01.01

Tahun 2019 tentang Penetapan Lembaga Pemasyarakatan Pilot Project Maximum Security, Medium Security, dan Minimum Security.

Peraturan Menteri Hukum dan Hak Asasi Manusia Republik Indonesia Nomor 35 Tahun 2018 tentang Revitalisasi Penyelenggaraan Pemasyarakatan.

Peraturan Menteri Hukum dan Hak Asasi Manusia Republik Indonesia Nomor M.HH-05.OT.01.01 Tahun 2011 tentang Perubahan atas Keputusan Menteri Kehakiman Nomor M.01PR.07.03 Tahun 1985 tentang Organisasi dan Tata Kerja Lembaga Pemasyarakatan.

Peraturan Menteri Hukum dan Hak Asasi Manusia Republik Indonesia Nomor 11 Tahun 2017 tentang Grand Design Penanganan Overcrowded pada Rumah Tahanan Negara dan Lembaga Pemasyarakatan.

Santoso, Singgih. (2018). Mahir Statistik Multivariat dengan SPPS. PT Elex Media Komputindo. Jakarta.

Schwab, Klaus. (2017). The Fourth Industrial Revolution. Crown Business. New York.

Undang - Undang Republik Indonesia

Nomor 12 Tahun 1995 tentang Pemasyarakatan.

Widhiastuti, Hardani. (2014). "Big Five Personality sebagai Prediktor Kreativitas dalam Meningkatkan Kinerja Anggota Dewan", Jurnal Psikologi, 41, 115-133 